\title{
ASSESSMENT OF EFFICIENCY OF ASBESTOS- CEMENT DUST COLLECTION BY DUST COLLECTORS WITH COUNTERCURRENT SWIRLING FLOWS
}

\author{
V.N. Azarov \\ Volgograd State Technical University \\ VSTU \\ Volgograd, Russian Federation \\ kaf_bgdvt@mail.ru
}

\author{
I.V. Stefanenko \\ Volgograd State Technical University \\ VSTU \\ Volgograd, Russian Federation \\ kaf_bgdvt@mail.ru
}

\author{
R.A. Burkhanova \\ Volgograd State Technical University \\ VSTU \\ Volgograd, Russian Federation \\ renata_vlg@mail.ru
}

\begin{abstract}
The authors have investigated the process of asbestos-cement dust slippage past dust collectors with countercurrent swirling flows. They took into account the mass rate of dust getting to the working zone air, the total gas flow rate, the length of the lower inlet branch duct, the conditional relative speed in the midsection of the apparatus, the ratio of the flow rates delivered to the upper and lower inlets, the distance between the axes of local exhausts, the relative concentration and particle size distribution of dust. In the course of the investigation, the methods of mathematical statistics and probabilistic-stochastic approach were applied. The optimal ratio of the given parameters was determined, at which the maximum dust collection efficiency was observed.
\end{abstract}

Keywords-dust collection efficiency, assessment of dust slippage, asbestos-cement dust, dust particle size distribution, dust collectors with countercurrent swirling flows

\section{INTRODUCTION}

Fine dust is formed in significant amounts at plants manufacturing asbestos-cement products. Due to the specific features of the structure of asbestos fibers and to the characteristic aspects of the manufacturing process, the finest fractions $\left(\mathrm{PM}_{10}, \mathrm{PM}_{2.5}\right)$ can not be collected [1]. At the same time, the concentration of asbestos-cement dust in the working zone air of some enterprises can exceed the maximum permissible concentration (MPC) by 5 times, while the concentration at the border of the enterprise sanitary protection zone is 2 times higher than the normative values [2].
To control the dust factor, cyclones, bag filters and apparatuses with countercurrent swirling flows (CSF) are used [3]. However, the processes of dust collection by means of countercurrent swirling flows apparatuses have not been completely studied yet.

It is necessary to carry out an assessment of asbestoscement dust slippage into the atmosphere and working zone air in order to develop a set of long-term decisions concerning the protection against dust releases at workplaces. Taking into account the current incompleteness of information on the work of countercurrent swirling flows apparatuses, the present paper has a goal to investigate the process of asbestos-cement dust collection by a countercurrent swirling flows apparatus with regard to the mass flow rate of the dust released to the working zone air, the total gas flow rate in the system, the length of the lower inlet branch duct, the conditional relative speed in the midsection of dust collector, the distance between the axes of local exhausts, the ratio of the flow rates at the lower and upper inlets, the relative concentration and particle size distribution of dust delivered for treatment, applying the methods of mathematical statistics and probabilistic-stochastic approach.

\section{ANALYSIS OF DUST PARTICLE SIZE DISTRIBUTION AT VARIOUS SEGMENTS OF THE SYSTEMS OF ASPIRATION AND GENERAL EXHAUST VENTILATION}

The authors took samples of dust from the aspiration systems of a moulding shop (at local exhausts of runners and at the spots past the cyclones), as well as from the system of 
general exhaust ventilation and the air of the sanitary protection zone. The enterprise manufacturing asbestoscement products is equipped with $\mathrm{CN}-15-700$ cyclones with the operational efficiency of $76 \%$. Fig. 1 shows the integral functions of dust particle mass distribution according to diameters at various spots of the aspiration systems, the system of general exhaust ventilation and in the sanitary protection zone, which were plotted in the probabilisticlogarithmic net based on the measurements results.

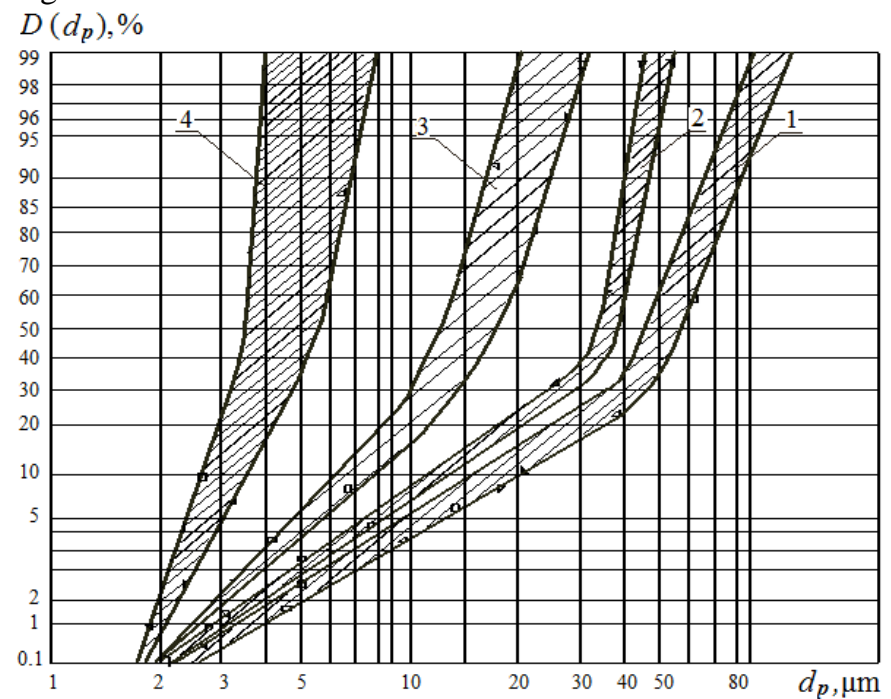

Fig. 1. The range of variation of integral functions of dust particle mass distribution according to diameters: 1 - in the aspiration system prior to the cyclone treatment; 2 - in the aspiration system after the cyclone treatment; 3 in the system of general exhaust ventilation; 4 - in the sanitary protection zone

The variance analysis showed that all the curves have the form of a truncated logarithmical curve. The median diameter $d_{50}$ varies within the limits from 30 to $50 \mu \mathrm{m}$, in the systems of general exhaust ventilation $d_{50}$ varies within the limits from 13 to $18 \mu \mathrm{m}$, and in the sanitary protection zone $d_{50}$ varies within the limits from 3.5 to $5.5 \mu \mathrm{m}$. The range of variation of dust fineness is from 2 to $90 \mu \mathrm{m}, \sigma_{\mathrm{av}}=4.8$. The poured density of dust amounts to $3.10-3.25 \mathrm{~g} / \mathrm{cm}^{3}$.

\section{PROGRAMME AND METHOD OF CONDUCTING THE EXPERIMENT}

To conduct the experiment, the authors used an installation comprising two apparatuses with countercurrent swirling flows and two exhausts (fig.1). According to the specific features of asbestos-cement dust, in order to prevent particle puffing, the optimal ratio of dust-gas mixture rates at the inlets of the duct-collecting installation was determined to be 60 to 40 while the regular one is 73 to 27 .

The form parameter from 0.5 to 5 was set for the tangential swirler that was used in the installation for the purpose of swirl creation and adjustment of the air flow passing through the air duct.

Inside the installation described, the asbestos-cement dust is delivered to the charging device and then the regulating shutter starts to open gradually. At the same time, the air flow from the air duct transports dust fractions. A researcher conducts observations over the dust particles motion to record the moment of dust deposition on the inner surface. The formation of dust deposits stops at a particular value of the speed (the dust of asbestos-cement in solid and gaseous phases mix together).

In order to conduct the assessment of dust particle slippage to the atmosphere and the working zone air after the treatment in a dust collector with countercurrent swirling flows, it is necessary to compare the mass values of the dust entering the system and of the dust removed from it [4,5].

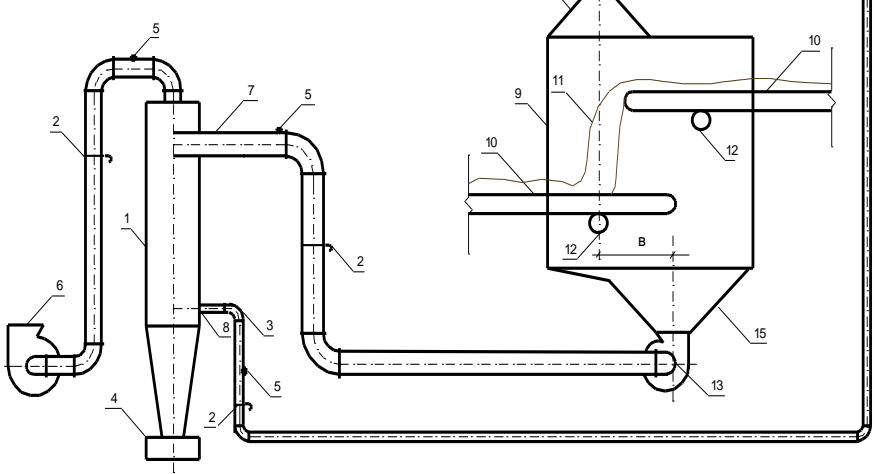

Fig. 2. The scheme of the experimental installation for the investigation of CSF apparatus efficiency at the initial position of the local exhaust axes: 1 CSF apparatus with countercurrent swirling flows; 2, - slide gates; 3 - swirler; 4 - dust collection chamber; 5 - fitting to carry out measurements; 6 ventilation fan, 7 - upper inlet of CSF apparatus; 8 - lower inlet of CSF apparatus; 9 - dedusting unit; 10 - conveying units, 11 - bulk material, 12 brushes; 13 - swirler, 14, 15 - upper and lower local exhausts

For the purpose of the investigation, it is necessary to choose the operation mode of the installation, which will allow for the continuous motion of gas flow. A correct spot for taking samples can be determined through selecting a straight downstream segment of the flow located significantly far from the segments where the flow direction or the cross-section area of the air duct change. The shortest length of such straight segment should not be less than its 5 equivalent diameters [6-8].

The area of the air duct under investigation is then divided into equal segments with a sampling spot at the centre of each. The measurements of the dynamic pressure should be performed no less than three times at each of the spots. The average dynamic pressure can be obtained through the results comparing at each of the spots under investigation. The authors took samples of dust at all the cross-sections selected for measurements at one and the same period of time.

Further, the investigation algorithm has the following stages: formulation of the objective; selection of response functions, the factors and levels of variation; selection of regression equation, decision on the necessary number of tests, generation of the design of multifactorial experiment; implementation of the investigation plan, obtaining of results; calculation of regression coefficients; calculation of the reproducibility variance and regression coefficients variance, assessment of the significance of regression coefficients; 
testing for the model adequacy; plotting of lines of equal levels, determination of the region of the optimum.

A theoretical analysis of dust collection process was carried out in the context of the probabilistic-stochastic approach with the help of the experimental design techniques [9]. The following variable factors were selected in the first part of the investigation: $L_{t}$ - total gas flow rate in the system $\left(\mathrm{m}^{3} / \mathrm{h}\right) ; L_{l} / L_{t}$ - proportion of gas rate delivered to the apparatus through the lower inlet; $C$ - relative concentration of dust delivered for treatment, $\left(\mathrm{g} / \mathrm{m}^{3}\right)$.

A complete factorial experiment was carried out by the authors at the first stage of the investigation. The following transformation [10-12] was used in the course of transfer from the planning matrix to the operational matrix of the experiment:

$$
x_{i}=\bar{t}_{i}-\bar{x}_{i 0} \not \Delta I_{i}
$$

where $x_{i}$ - coded value of the factor; $\bar{x}_{i}$ - natural value of the factor; $\bar{x}_{i_{0}}-$ natural value of the intermediate level; $I_{i}-$ variability interval for factor values.

The levels and intervals of variability of the determining factors are given in table 1.

TABLE I. THE EXPERIMENT DESIGN

\begin{tabular}{|c|c|c|c|c|}
\hline \multirow[b]{2}{*}{ Factors } & \multirow[b]{2}{*}{$\begin{array}{c}\text { Variability } \\
\text { intervals }\end{array}$} & \multicolumn{3}{|c|}{ Levels of factors } \\
\hline & & $\begin{array}{c}\text { Intermediate } \\
0\end{array}$ & $\begin{array}{c}\text { High } \\
+1\end{array}$ & $\begin{array}{c}\text { Low } \\
-1\end{array}$ \\
\hline $\begin{array}{l}x_{1}-\text { total gas flow rate in } \\
\text { the system, } \mathrm{m}^{3} / \mathrm{h}\end{array}$ & 20 & 100 & 120 & 80 \\
\hline $\begin{array}{l}x_{2}-\text { proportion of the gas } \\
\text { rate delivered to the } \\
\text { apparatus through the } \\
\text { lower inlet }\end{array}$ & 0.1 & 0.3 & 0.4 & 0.2 \\
\hline $\begin{array}{l}x_{3}-\text { relative } \\
\text { concentration of dust } \\
\text { delivered for treatment, } \\
\text { taken relative to } 1 \mathrm{~g} / \mathrm{m}^{3}\end{array}$ & 20 & 40 & 60 & 20 \\
\hline
\end{tabular}

TABLE II. THE EXPERIMENT DESIGN

\begin{tabular}{|l|c|c|c|c|}
\hline \multirow{2}{*}{ Factors } & \multirow{2}{*}{$\begin{array}{c}\text { Variability } \\
\text { intervals }\end{array}$} & $\begin{array}{c}\text { Lntermediate } \\
\mathbf{0}\end{array}$ & $\begin{array}{c}\text { High } \\
+\mathbf{1}\end{array}$ & $\begin{array}{c}\text { Low } \\
\mathbf{- 1}\end{array}$ \\
\hline $\begin{array}{l}V_{\mathrm{c}}-\text { conditional relative } \\
\text { speed in the midsection of } \\
\text { apparatus }\end{array}$ & 2.00 & 5.50 & 7.50 & 3.50 \\
\hline $\begin{array}{l}B-\text { distance between the } \\
\text { axes of local exhausts }\end{array}$ & 0.25 & 0.75 & 1.00 & 0.50 \\
\hline $\begin{array}{l}K_{l}-\text { ratio of the rates } \\
\text { delivered to the lower and } \\
\text { upper inlets }\end{array}$ & 0.05 & 0.25 & 0.30 & 0.20 \\
\hline
\end{tabular}

The following variable factors were selected in the second part of the investigation: $V_{c}$ - conditional relative speed in the midsection of dust collector, which is determined through the expression $V_{c}=L_{\Sigma} /\left(3600 F_{\text {mid sec }}\right)$ and taken relative to $1 \mathrm{~m} / \mathrm{s} ; B$
- distance between the axes of local exhausts; $K_{l}$ - ratio of the rates delivered to the lower and upper inlets $K_{l}=L_{l} / L_{l}$.

The levels and variability intervals of the determining factors are given in table 2.

\section{MAIN RESULTS OF THE EXPERIMENTAL INVESTIGATION}

The conducted investigations carried out according to the experiment design (tables 1.2) taking into account the time drift and randomization [13-16] allowed obtaining the data presented in tables 3, 4 .

TABLE III. THE RESULTS OF THE EXPERIMENTAL INVESTIGATIONS OF THE PERFORMANCE OF THE SYSTEM OF ASBESTOS-CEMENT DUST COLLECTION BY MEANS OF CSF APPARATUS DEPENDING ON THE TOTAL GAS FLOW RATE IN THE SYSTEM, THE PROPORTION OF THE GAS RATE DELIVERED TO THE APPARATUS THROUGH THE LOWER INLET, THE RELATIVE CONCENTRATION OF DUST DELIVERED FOR TREATMENT, AND THE LENGTH OF THE BRANCH DUCT OF THE LOWER INLET

\begin{tabular}{|c|c|c|c|c|}
\hline Mode & $\begin{array}{c}\text { Total gas } \\
\text { flow rate } \\
\text { in the } \\
\text { system, } \\
\mathbf{m}^{3} / \mathbf{h}\end{array}$ & $\begin{array}{c}\text { Proportion } \\
\text { of gas rate, } \\
\text { delivered to } \\
\text { the } \\
\text { apparatus } \\
\text { through the } \\
\text { lower inlet }\end{array}$ & $\begin{array}{c}\text { Relative } \\
\text { concentration } \\
\text { of dust } \\
\text { delivered for } \\
\text { treatment, } \\
\mathrm{g} / \mathrm{m}^{\mathbf{3}}\end{array}$ & $\begin{array}{l}\text { Dust collection } \\
\text { efficiency, \% }\end{array}$ \\
\hline \multirow{27}{*}{$L=1 D$} & \multirow{9}{*}{80} & \multirow{3}{*}{0.2} & 89.71 & 75.75 \\
\hline & & & 89.89 & 75.76 \\
\hline & & & 89.93 & 75.79 \\
\hline & & \multirow{3}{*}{0.3} & 90.08 & 75.67 \\
\hline & & & 90.17 & 75.68 \\
\hline & & & 90.25 & 75.69 \\
\hline & & \multirow{3}{*}{0.4} & 90.09 & 75.50 \\
\hline & & & 90.19 & 75.51 \\
\hline & & & 90.29 & 75.52 \\
\hline & \multirow{9}{*}{100} & \multirow{3}{*}{0.2} & 90.12 & 75,85 \\
\hline & & & 90.24 & 75.88 \\
\hline & & & 90.35 & 75.90 \\
\hline & & \multirow{3}{*}{0.3} & 90.41 & 75.76 \\
\hline & & & 90.53 & 75.77 \\
\hline & & & 90.64 & 75.78 \\
\hline & & \multirow{3}{*}{0.4} & 90.49 & 75.59 \\
\hline & & & 90.59 & 75.60 \\
\hline & & & 90.69 & 75.61 \\
\hline & \multirow{9}{*}{120} & \multirow{3}{*}{0.2} & 91.28 & 76.00 \\
\hline & & & 91.34 & 76.01 \\
\hline & & & 91.46 & 76.02 \\
\hline & & \multirow{3}{*}{0.3} & 91.52 & 75.85 \\
\hline & & & 91.65 & 75.86 \\
\hline & & & 91.74 & 75.87 \\
\hline & & \multirow{3}{*}{0.4} & 91.59 & 75.68 \\
\hline & & & 91.69 & 75.69 \\
\hline & & & 91.79 & 75.70 \\
\hline
\end{tabular}


TABLE III. CONT.

\begin{tabular}{|c|c|c|c|c|}
\hline \multirow{27}{*}{$L=2 D$} & \multirow{9}{*}{80} & \multirow{3}{*}{0.2} & 89.71 & 78.71 \\
\hline & & & 89.89 & 78.89 \\
\hline & & & 89.93 & 78.93 \\
\hline & & \multirow{3}{*}{0.3} & 90.08 & 79.08 \\
\hline & & & 90.17 & 79.17 \\
\hline & & & 90.25 & 79.25 \\
\hline & & \multirow{3}{*}{0.4} & 90.09 & 79.09 \\
\hline & & & 90.19 & 79.19 \\
\hline & & & 90.29 & 79.29 \\
\hline & \multirow{9}{*}{100} & \multirow{3}{*}{0.2} & 90.12 & 79.12 \\
\hline & & & 90.24 & 79.24 \\
\hline & & & 90.35 & 79.35 \\
\hline & & \multirow{3}{*}{0.3} & 90.41 & 79.41 \\
\hline & & & 90.53 & 79.53 \\
\hline & & & 90.64 & 79.64 \\
\hline & & \multirow{3}{*}{0.4} & 90.49 & 79.49 \\
\hline & & & 90.59 & 79.59 \\
\hline & & & 90.69 & 79.69 \\
\hline & \multirow{9}{*}{120} & \multirow{3}{*}{0.2} & 91.28 & 80.28 \\
\hline & & & 91.34 & 80.34 \\
\hline & & & 91.46 & 80.46 \\
\hline & & \multirow{3}{*}{0.3} & 91.52 & 80.52 \\
\hline & & & 91.65 & 80.65 \\
\hline & & & 91.74 & 80.74 \\
\hline & & \multirow{3}{*}{0.4} & 91.59 & 80.59 \\
\hline & & & 91.69 & 80.69 \\
\hline & & & 91.79 & 80.79 \\
\hline \multirow{27}{*}{$L=3 D$} & \multirow{9}{*}{80} & \multirow{3}{*}{0.2} & 89.71 & 73.11 \\
\hline & & & 89.89 & 73.39 \\
\hline & & & 89.93 & 73.53 \\
\hline & & \multirow{3}{*}{0.3} & 90.08 & 73.70 \\
\hline & & & 90.17 & 73.90 \\
\hline & & & 90.25 & 74.10 \\
\hline & & \multirow{3}{*}{0.4} & 90.09 & 74.20 \\
\hline & & & 90.19 & 74.40 \\
\hline & & & 90.29 & 74,60 \\
\hline & \multirow{9}{*}{100} & \multirow{3}{*}{0.2} & 90.12 & 74,92 \\
\hline & & & 90.24 & 75,14 \\
\hline & & & 90.35 & 75,35 \\
\hline & & & 90.41 & 75.50 \\
\hline & & 0.3 & 90.53 & 75.70 \\
\hline & & & 90.64 & 75.90 \\
\hline & & & 90.49 & 76.00 \\
\hline & & 0.4 & 90.59 & 76.20 \\
\hline & & & 90.69 & 76.40 \\
\hline & & & 91.28 & 7.48 \\
\hline & & 0.2 & 91.34 & 7.64 \\
\hline & & & 91.46 & 77.86 \\
\hline & & & 91.52 & 78.00 \\
\hline & 120 & 0.3 & 91.65 & 78.20 \\
\hline & & & 91.74 & 78.40 \\
\hline & & & 91.59 & 78.50 \\
\hline & & 0.4 & 91.69 & 78.70 \\
\hline & & & 91.79 & 78.90 \\
\hline
\end{tabular}

TABLE IV. THE RESULTS OF THE EXPERIMENTAL INVESTIGATION OF THE PERFORMANCE OF THE SYSTEM OF ASBESTOS-CEMENT DUST COLLECTION DEPENDING ON THE CONDITIONAL RELATIVE SPEED IN THE MIDSECTION OF THE APPARATUS, ON THE RATIO OF THE RATES DELIVERED TO THE LOWER AND UPPER INLETS, AND THE DISTANCE BETWEEN THE LOCAL EXHAUSTS AXES

\begin{tabular}{|c|c|c|c|}
\hline $\begin{array}{c}\text { Conditional } \\
\text { relative speed } \\
\text { in the } \\
\text { midsection of } \\
\text { the apparatus, } \\
\mathrm{m} / \mathrm{s}\end{array}$ & $\begin{array}{l}\text { Ratio of the } \\
\text { rates delivered } \\
\text { to the lower } \\
\text { and upper } \\
\text { inlets }\end{array}$ & $\begin{array}{c}\text { Distance } \\
\text { between the } \\
\text { local exhausts } \\
\text { axes, m }\end{array}$ & $\begin{array}{l}\text { Dust collection } \\
\text { efficiency } \eta, \%\end{array}$ \\
\hline 1 & 2 & 3 & 4 \\
\hline \multirow{9}{*}{3.5} & \multirow{3}{*}{0.2} & 0.5 & 0.864 \\
\hline & & 0.75 & 0.861 \\
\hline & & 1 & 0.850 \\
\hline & \multirow{3}{*}{0.25} & 0.5 & 0.869 \\
\hline & & 0.75 & 0.867 \\
\hline & & 1 & 0.866 \\
\hline & \multirow{3}{*}{0.3} & 0.5 & 0.862 \\
\hline & & 0.75 & 0.858 \\
\hline & & 1 & 0.852 \\
\hline \multirow{6}{*}{5.5} & \multirow{3}{*}{0.2} & 0.5 & 0.903 \\
\hline & & 0.75 & 0.898 \\
\hline & & 1 & 0.894 \\
\hline & \multirow{3}{*}{0.25} & 0.5 & 0.928 \\
\hline & & 0.75 & 0.921 \\
\hline & & 1 & 0.912 \\
\hline \multirow{3}{*}{5.5} & \multirow{3}{*}{0.3} & 0.5 & 0.909 \\
\hline & & 0.75 & 0.900 \\
\hline & & 1 & 0.897 \\
\hline \multirow{9}{*}{7.5} & \multirow{3}{*}{0.2} & 0.5 & 0.872 \\
\hline & & 0.75 & 0.868 \\
\hline & & 1 & 0.864 \\
\hline & \multirow{3}{*}{0.25} & 0.5 & 0.878 \\
\hline & & 0.75 & 0.870 \\
\hline & & 1 & 0.868 \\
\hline & \multirow{3}{*}{0.3} & 0.5 & 0.869 \\
\hline & & 0.75 & 0.863 \\
\hline & & 1 & 0.860 \\
\hline
\end{tabular}

\section{ANALYSIS OF THE INVESTIGATION RESULTS AND CONCLUSIONS}

According to $[17,18]$, the variances were assessed, the regression equation coefficients were determined as well as the confidential interval for each of the experiment factors and the mean squared error.

The obtained results showed that the interaction coefficients are significant, and the linear model is inadequate. With regard to these facts, a conclusion was drawn on the necessity of the approximation of the response function by second order polynomials [9, 12-15]. In order to get the mathematical model of the region of optimum in the form of a second order equation, the orthogonal central composite design of the second order was realized at the second stage of the experiment.

The assessment of the reproducibility of the investigation was carried out based on the comparison of the calculated and tabulated values of Cochran's test. In order to assess the experiment process reproducibility and to carry out the statistical evaluation of the results, two parallel series of tests were planned in the course of the experiment design development. For that purpose, it was planned to perform two measurements at each combination of levels of the determining factors. After that, applying the 
«NonlinearEstimation» module in the "Statistica" software package for statistical analysis, the regression equation in the form of a second order polynomial was determined for each response, the coefficient significance was verified based on the Student's test; then insignificant coefficients were excluded for the confidence level of 0.05 , and the adequacy of the obtained equations was tested on the basis of Fisher's variance, for which the predicted response values were determined.

The efficiency of dust collecting installation was taken as the response function in all the measurements [14, 19, 20]. The results of the experimental investigation are wellreproducible. In the first part of the investigation, the regression equation was obtained in the following form as a result of the approximation of the experimental data by second order polynomials with regard to the significance of the calculated coefficients:

$$
\begin{gathered}
\eta=\eta\left(L_{t}, L_{l} / L_{t}, C\right) \\
\eta=82.755-5 L_{t}-17.2 L_{\ell} / L_{t}-2 C-0.08 L_{t}^{2}
\end{gathered}
$$

The results of the assessment of asbestos-cement dust slippage past CSF apparatuses for the mode of $L=1 D$ (with the length of the lower inlet branch duct $L=150 \mathrm{~mm}$ ) are given in fig. 3 .

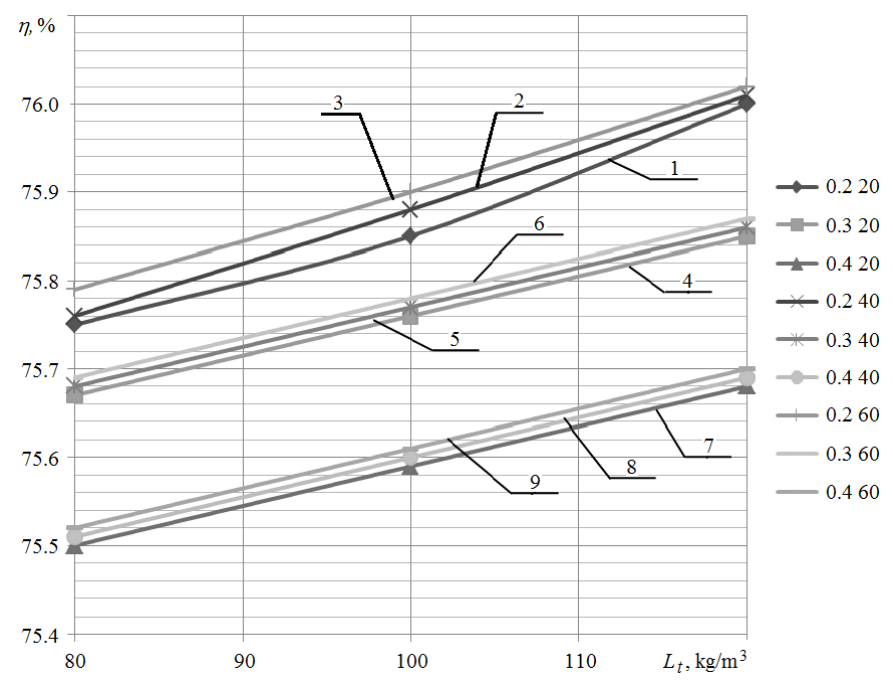

Fig. 3. Experimental dependences of the efficiency of asbestos-cement dust collection by $C S F-150$ apparatus with countercurrent swirling flows, with the length of the lower inlet branch duct $\mathrm{L}=150 \mathrm{~mm}$, at: $C=20: 1-L_{\mathrm{l}} / L_{t}=0.2$; $2-L_{/} / L_{t}=0.3 ; 3-L_{/} / L_{t}=0.4 ; C=40: 4-L_{l} / L_{t}=0.2 ; 5-L_{/} / L_{t}=0.3$; $6-L_{l} / L_{t}=0.4 ; C=60: 7-L_{l} / L_{t}=0.2 ; 8-L_{l} / L_{t}=0.3 ; 9-L_{l} / L_{t}=0.4$

The results of the assessment of asbestos-cement dust slippage past CSF apparatuses for the mode of $L=2 D$ (with the length of the lower inlet branch duct $L=300 \mathrm{~mm}$ ) are given in fig. 4 .

In this case, the regression equation will have the form:

$$
\begin{gathered}
\eta=83.99-5 L_{t}+14.2 L_{l} / L_{t}-2 C-3.27 \cdot 10^{-4}\left(L_{l} / L_{t}\right)^{2}- \\
-2.6 \cdot 10^{-3} L_{t}\left(L_{l} / L_{t}\right)
\end{gathered}
$$

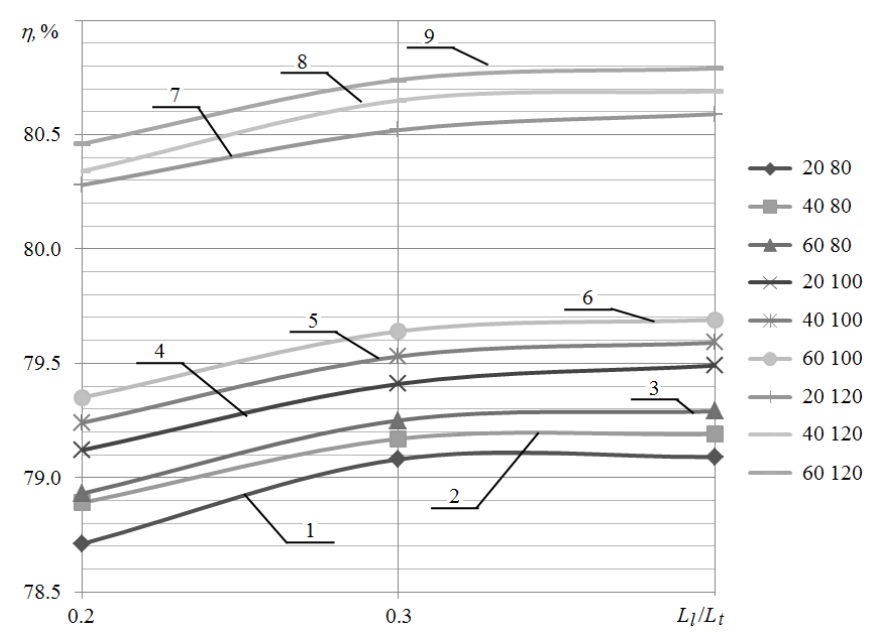

Fig. 4. Experimental dependences of the efficiency of asbestos-cement dust collection by $C S F-150$ apparatus with countercurrent swirling flows, with the length of the lower inlet branch duct $\mathrm{L}=300 \mathrm{~mm}$, at: $L_{t}=80: 1-C=20 ; 2-C$ $=40 ; 3-C=60 ; L_{t}=100: 4-C=20 ; 5-C=40 ; 6-C=60 ; L_{t}=120: 7-C$ $=20 ; 8-C=40 ; 9-C=60$

The results of the efficiency assessment of asbestoscement dust collection by CSF apparatuses for the mode of $L=3 D$ (with the length of the lower inlet branch duct $L=450$ $\mathrm{mm})$ are given in fig.5.

In this case, the regression equation will have the form:

$$
\begin{gathered}
\eta=74.42-4.995 L_{t}+49.7 L_{/} / L_{t}-1.999 C-2.27 \cdot 10^{-2} L_{t}^{2}- \\
-7 \cdot 10^{-4} L_{t}\left(L_{l} / L_{t}\right)
\end{gathered}
$$

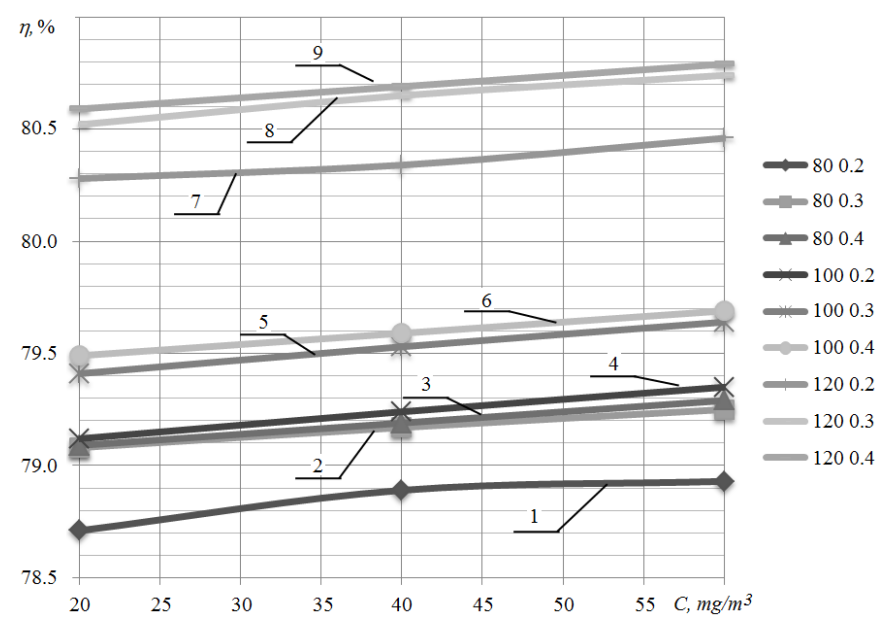

Fig. 5. Experimental dependences of the efficiency of asbestos-cement dust collection by $C S F-150$ apparatus with countercurrent swirling flows, with the length of the lower inlet branch duct $L=450$, at: $L_{t}=80: 1-L_{l} / L_{t}=0.2 ; 2-$ $L_{l} / L_{t}=0.3 ; 3-L_{l} / L_{t}=0.4 ; L_{t}=100: 4-L_{l} / L_{t}=0.2 ; 5-L_{l} / L_{t}=0.3 ; 6-L_{l} / L_{t}=$ $0.4 ; L_{t}=120: 7-L_{l} / L_{t}=0.2 ; 8-L_{l} / L_{t}=0.3 ; 9-L_{l} / L_{t}=0.4$

The results of the assessment of the system efficiency depending on the conditional relative speed in the midsection of CSF apparatus, and on the ratio of the air rates delivered to 
the upper and lower inlets, obtained in the second part of the investigation, are given in figures 6 and 7, respectively.

In the second part of the experiment, the regression equation has the form:

$$
\eta=\eta\left(V_{c}, K_{l}, B\right)
$$

$$
\eta=0.89+0.17 V_{c}-0.02 V_{c}^{2}+2.3 K_{l}-4.55 K_{l}^{2}-0.2 B
$$

Thus, according to the results of the first part of the experimental investigation of dust released in the process of asbestos-cement products manufacturing, the highest efficiency of dust collection is registered at the ratio of the rates at the lower and upper inlets equaling to 0.2 ; at the total gas flow rate in the system equaling to $120 \mathrm{~m}^{3} / \mathrm{h}$ and the relative concentration of dust delivered for treatment belonging to the range of 40 to $60 \mathrm{~g} / \mathrm{m}^{3}$.

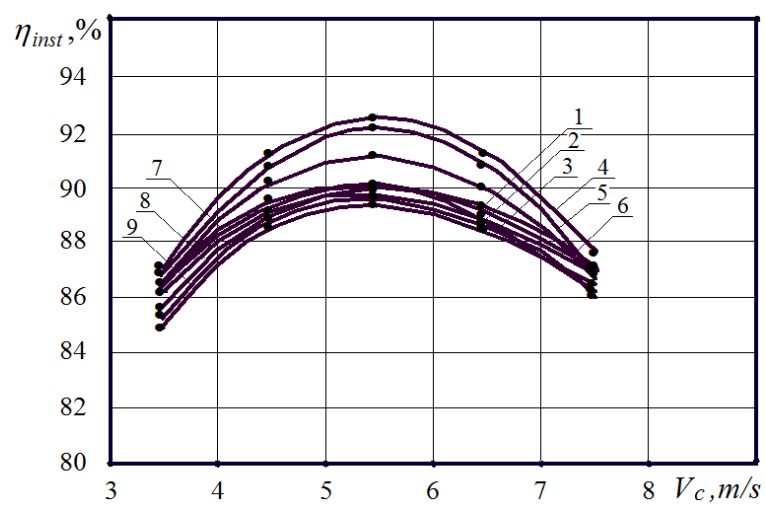

Fig. 6. Dependence of the collecting efficiency of the installation on the conditional relative speed in the midsection of the apparatus at $K_{l}=0.2: 1$ $B=0.5 ; 2-B=0.75 ; 3-B=1$; at $K_{l}=0.25: 4-B=0.5 ; 5-B=0.75 ; 6-B=1$; at $K_{l}=0.3: 7-B=0.5 ; 8-B=0.75 ; 9-B=1$

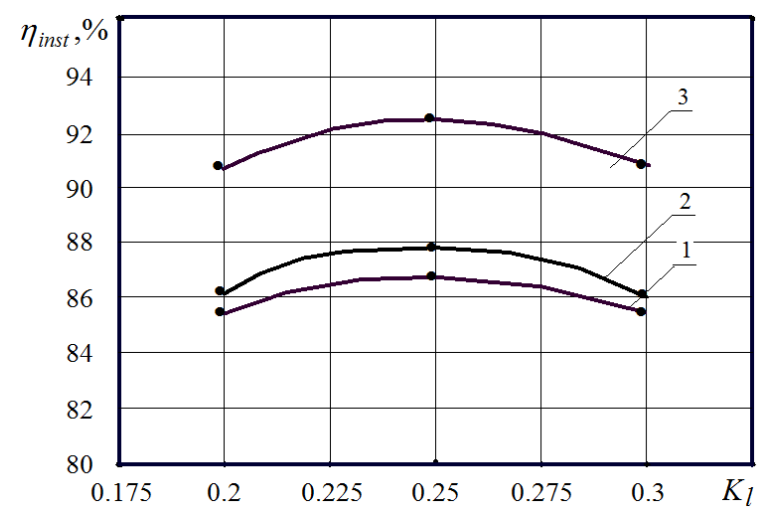

Fig. 7. Dependence of the collecting efficiency of the installation on the ratio of the air rates delivered to the upper and lower inlets of CSF apparatus: 1 - at $V_{c}=3.5 ; 2-$ at $V_{c}=7.5 ; 3-$ at $V_{c}=5.5$

Based on the second part of the experimental investigation, the highest efficiency of the collection, the dust released in the process of asbestos-cement products manufacturing occurs at the following values of the factors under investigation:

- at the distance of $0.5 \mathrm{~m}$ between the axes of the local exhausts;

- at the ratio of the rates delivered to the lower and upper inlets being within the range of 0.23 to 0.27 ;

- at the conditional relative speed being within the range of 5.3 to $5.8 \mathrm{~m} / \mathrm{s}$.

\section{References}

[1] V.N. Azarov, I.V. Stefanenko, R.A. Burkhanova, "On the Regularities of the Concentration Profile of Asbestos-Cement Dust, its Particle Size Distribution Depending on the Height of Working Room and the Methods of Air Exchange Organization", Applied Mechanics and Materials, vol. 875, pp. 187-190, January 2018 [The 2nd International Conference Material Engineering and Application, p.192, 2017].

[2] R.A. Burkhanova, N.A. Marinin, O.V. Burlachenko "On the investigation of aerodynamic characteristics of asbestos-cement dust in working zone air", Internet-Vestnik VolgGASU of Volgograd State University of Architecture and Civil Engineering, Internet Journal, Multi-Topic Series, vol. 1(20), January 2012.

[3] A.B. Lapshin, Dedusting technology for cement manufacturing. Novosibirsk: Stromekologiya, 1996, pp. 34-36.

[4] G.I. Barenblatt, On the motion of suspended particles in a turbulent flow. Moscow: Metallurgizdat, 1970, pp. 21-23.

[5] E.I. Boguslavsky, "Probabilistic-statistical method of the solution of dust-aeromechanics problems", Issues of labour protection, pp. 195-198, May 1986 [International Scientific Conference VMSI, p. 346, 1986].

[6] O.N. Zaytsev, "Countercurrent displaced swirling flows in multi-stage dust collectors", Eco technologies and resources saving, vol. 3, pp. 7879, March 2002.

[7] M.G. Ziganshin, A.A. Kolesnik, V.N. Posokhin, Design of dust-and-gas treatment apparatuses. Moscow: Ekopress-ZM, 1998, pp. 133-135.

[8] A.M. Dmitriev, Processes and technology of dedusting in cement industry. Moscow: NIIcement, 1984, p. 14.

[9] Y.P. Adler, Planning of Experiment. Moscow: Nauka Publishers, 1966, pp. 92-93.

[10] A.M. Kutepov, A.S. Latkin, Vortex processes for dispersion systems modification. Moscow: Nauka Publishers, 1999, pp. 211-212.

[11] I.N. Logachev, K.I. Logachev, "On the prediction of particle size distribution and concentration of coarsely dispersed aerosols in local exhausts of aspiration systems", News of higher educational institutions. Construction, vol.9, pp. 85-90, September 2002.

[12] V.N. Azarov, "Dust particle size distribution as random function", Obyedinenny Nauchny Zhurnal (Integrated Scientific Journal), vol. 6, pp. 62-64, June 2003.

[13] V.N. Azarov, D. P. Borovkov, A. M. Redhwan, "Application of swirling flows in aspiration systems", International Review of Mechanical Engineering, vol. 8, N. 4, pp. 750-753, October 2014.

[14] V.N. Azarov, D.V. Lukanin, D.P. Borovkov, A.M. Redhwan "Experimental study of secondary swirling flow influence on flows structure at separation chamber inlet of dust collector with counter swirling flows", International Review of Mechanical Engineering, vol. 8, N. 5, pp. 851-856, October 2014.

[15] I. N. Logachev, K. I. Logachev, O.A. Averkova, V.N. Azarov, "Methods of reducing the power requirements of ventilation systems", Refractories and Industrial Ceramics, vol. 55, issue 4, pp. 365-370, December 2014.

[16] V.N. Azarov, N.V. Menzelitseva, N.Yu. Karapuzova, A.M. Redhwan "Main Trends of Conditions Normalizing at Cement Manufacturing Plants", International Review of Civil Engineering, vol. 6, N. 6, pp. 140-145, June 2015. 
[17] V.N. Azarov, S.A. Koshkarev "Evaluation of wet dust separator effectiveness in the dedusting of emissions from expanded clay kiln", Magazine of Civil Engineering, vol. 54(2), pp. 18-32, February 2015.

[18] V.N. Azarov, A.I. Evtushenko, V.P. Batmanov, A.B. Strelyaeva "Aerodynamic characteristics of dust in the emissions into the atmosphere and working zone of construction enterprises", International Review of Civil Engineering, vol. 7, N. 5, pp. 132-136, September 2016.

[19] V.N. Azarov, S.A. Koshkarev, D.V. Azarov "The Decreasing Dust Emissions of Aspiration Schemes Applying a Fluidized Granular Particulate Material bed Separator at the Building Construction
Factories", Procedia Engineering, vol. 165, pp. 1070-1079, September 2016 [15th International scientific conference "Underground Urbanisation as a Prerequisite for Sustainable Development”, p.1930, 2016].

[20] V.N. Azarov, I.V. Stefanenko, R.A. Burkhanova "Research of Aerodynamic Characteristics of Asbestos-Cement Dust in the Ventilation Emissions to the Atmosphere", Applied Mechanics and Materials, vol. 878, pp. 251-254, February 2018 [International Conference "Civil, Architectural, Structural and Constructional Engineering II", p. 323, 2017]. 